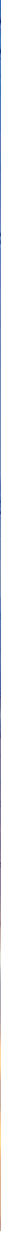

\title{
DIGITAL GRIDS BEYOND SMART GRIDS CHALLENGES TO MAKE FUTURE ELECTRIC GRIDS STABLE AND RESILIENT
}

I Jose Luis Domínguez-García - DOI: https://doi.org/10.1051/epn/2021506

- Catalonia Institute for Energy Research (IREC) - Jardins de les Dones de Negre $12^{\text {nd }}$ floor - Sant Adrià de Besòs, Spain

Novel technologies are changing our understanding of the electrical grid. These novel concepts, including power electronics, energy storage, ICT and renewable energy make the electrical grid highly controllable but at the same time also vulnerable. The future grid will introduce novel dynamics, stability challenges and security issues to be handled.

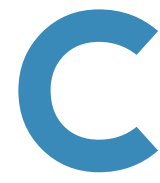

urrent energy systems were designed more than 100 years ago and have been only incrementally modified since. They worked well in the time of vertically integrated, centrally supplied generation models, but this was when efficiency and resilience were less important. In addition, the $\mathrm{EU}$ is targeting to reduce the emission of greenhouse gasses to net zero by 2050 according to COP $25^{1}$ in Madrid. The potential contribution of the power sector to realising these goals through the integration of renewable energy sources (RES) is highly significant. Indeed, the high reliance on

https://home.kpmg/xx/en/home/insights/2019/12/key-outcomes-of-cop25.html
RES and the electrification of energy sectors as a key factor in tackling undesired climate change was underscored in COP24 Katowice [1]. In fact, some future European energy scenarios even foresee a RES penetration close to $100 \%$ by 2050 [2]. In order to achieve this ambitious RES penetration target, RES and other elements will have to strongly support all aspects of power system stability as well as security of the electricity supply.

\section{Energy Grid disruption}

The electricity sector is changing its paradigm making it necessary to adapt the industrial sector to such a new model. The change is led by the irruption of the renewable 
energies, energy storage, the integration of technologies of information and communication and internet, which has provoked the evolution of the classic distribution grid to the Smart Grid, and now beyond that to the Digital Grid.

The digital grid is the digitisation of electricity networks using advanced technology. It allows two-way communication between the utility and the network, including its customers, and enables insight, automation and control across the utilities' operations, empowering utilities to improve reliability, availability and efficiency of the grid. The Digital Grid is the concept aiming to connect decentralised power from renewables, microgrids and virtual power plants, as well as energy storage alongside traditional bulk generation; to harness the potential of connected homes and devices and the internet of things as well as improve the reliability of current grids by making them smarter, able to self-detect and self-heal outages, and to re-route power as needed.

The Digital Grid concept is a key part of the future electrical grid and increases system complexity since it interrelates the electrical system with the communication network. The evolution of the future electrical grid on the distribution network especially in urban areas may include enhanced communication capabilities. The penetration of renewable energies and energy storage leads to the application of mini and micro-grids such as those for small communities, large buildings or manufacturing facilities.

\section{Electrical Grid modelling:} new dynamic behaviour

Classical electrical grid dynamics are governed by large synchronous generators with large inertia. These electrical systems have been commonly modelled and represented, in a highlevel way, as a group of interacting oscillators which could be modelled for example as a Kuramoto-like model [3]. However, the future electrical grid with the introduction of novel highly non-linear elements and inertia reduction, is changing such behaviour and the stability concepts and definitions [4]. Different time-frames and frequencies will be interacting. In the $\bullet \bullet \bullet$

v FIG. 1: High-level representation of a Future Electrical Grid, including distributed management; a highly flexible and meshed grid.
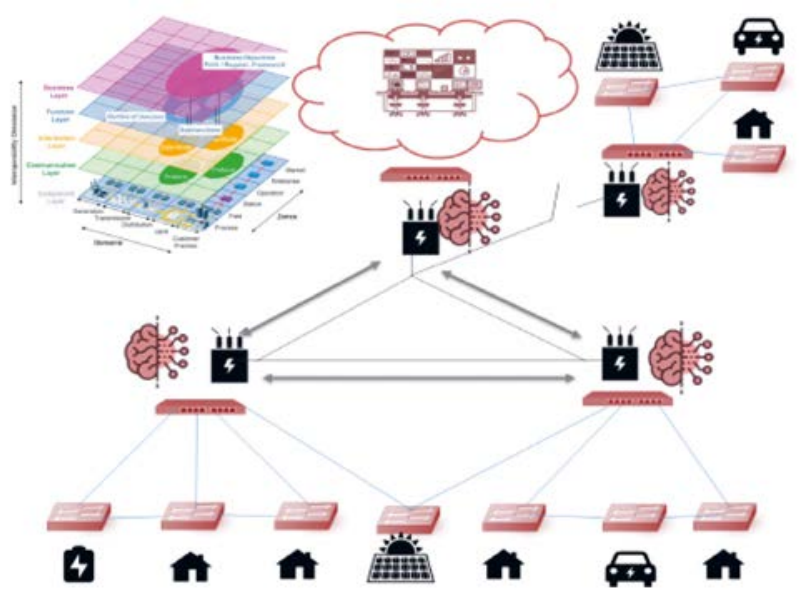

\section{THE FUTURE DEPENDS ON OPTICS}

(1)

Edmund Optics ${ }^{\oplus}$

The One-Stop Shop for All Your Optics Needs

- Extensive inventory with over 34.000 products in stock

- New products added continually

- High quality precision products for all your optics, imaging and photonics needs

- Technical support team on hand to help you choose the right product for your application

Browse our extensive online catalog today:

www.edmundoptics.eu

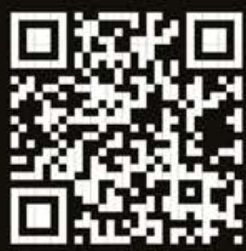

UK: $+44(0) 1904788600$

GERMANY: $+49(0) 61315700-0$

FRANCE: +33 (0) 820207555

sales@edmundoptics.eu

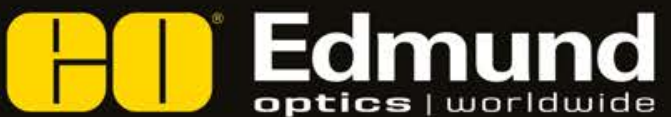




$$
\begin{array}{r}
\text { PFG. 2: } \\
\text { High-level } \\
\text { representation } \\
\text { of clusterisation } \\
\text { and self-healing } \\
\text { concept grid based } \\
\text { on a grid form by } \\
\text { microgrids [5]. Each } \\
\text { microgrid, compound } \\
\text { by renewable } \\
\text { sources, energy } \\
\text { storage and loads, is } \\
\text { isolated to operate } \\
\text { autonomously. In this } \\
\text { way, the electrical } \\
\text { grid will become } \\
\text { a grid of grids. }
\end{array}
$$

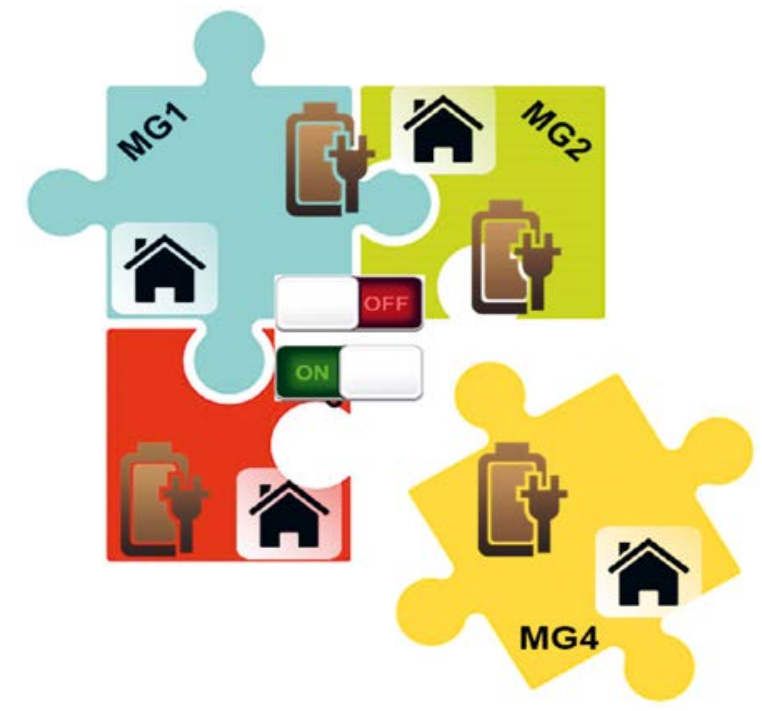

- - same way, different physical worlds like Alternate Current (AC) and Direct Current (DC) will be connected and decoupled at the same time by the power converters. Power converters are switching-based elements with high frequency responses and non-linearities increasing system stability complexity. Additionally, the Digital Grid has a direct interaction with the communication network which also poses restrictions and adds complexity due to its discrete nature within a continuous operation world. To understand and control such novel dynamic behaviour and the related risks and limitations including stability, synchronisation etc, is of great relevance.

\section{Electrical system resilience}

The electrical grid is considered one of the central critical infrastructures which needs to be protected. In this regard, a key aspect is ensuring its resilience taking advantage of the novel capabilities that the new technologies integrated on the grid may bring. One of the key elements leading to increased resilience and security is the novel grid automation system and monitoring devices which provide high visibility of grid status as well as give the opportunity to modify it. In this regard, microgrids and nano-grids may play a key role. These grids are intended to be more or less self-sufficient in terms of power generation and may be key elements for increased resilience. In addition, the application of Internet-of-Things-based elements - both as devices and protocols - allows the acquisition of increased amounts of data and data sharing among components.

In this line, different key developments are required aiming to deal with the resilience-cycle phases such as planning, detection, actuation/mitigation and recovery. For improving planning, there is the need to take advantage of previous information and knowledge, in order to anticipate and prepare the grid for such disruptions; in this sense, risk assessments tools [5] are required in order to identify and predict the vulnerable zones of the electrical network. Then, when an event occurs, there is the need to detect what happened. In the electrical grid, some events may result in similar disruptions from the electrical perspective, but the potential response and correction will be different. Thus, fault identification and location techniques [6] may help to determine what happened; speeding up the process of potential correction. To do this, the novel sensors and Artificial Intelligence will be of relevance. Then, we need to actuate to mitigate the impact of the disruption by responding and adapting the electrical grid. This can be achieved by isolating the impacted elements and reconfiguring the lines for ensuring the power flow (self-healing) or in case of special type of grids, take advantage of microgrid concepts and split the grid in small, stable, secure pieces (clusterisation) [7]. Finally, there is the need to recover the grid to its previous normal operational stage, which require coordination and synchronisation of the grid elements in order to ensure secure and stable reconnection.

\section{What else can we expect?}

The electrical grid is experiencing a rapid evolution. It has been a quite classical system for many years, and in the last 15 it has been transformed. It is expected to continue like this in the coming years by absorbing and integrating novel technologies. Leading us to the final question: What else we can expect?

\section{About the author}

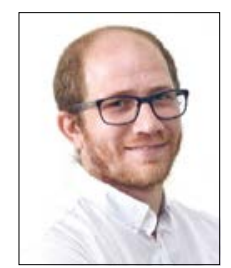

Jose Luis Domínguez-García is head of the Power Systems Group of the Catalonia Institute for Energy Research (IREC). His work deals with the grid integration of renewable energy sources, smart grids, and microgrids. He is the general coordinator of the H2020 COREWIND and INCITE H2020 MSCA ITN project.jldominguez@irec.cat

\section{REFERENCES}

[1] CarbonBrief 'COP24: Key outcomes agreed at the UN climate talks in Katowice' Accessed: $22^{\text {nd }}$ Dec. 2018, https://www.carbonbrief.org/cop24-key-outcomes-agreedat-the-un-climate-talks-in-katowice]

[2] E. Roadmap, "2050," Communication from the Commission to the European Parliament, the European Economic and Social Committee and the Committee of the Regions, Brussels, vol. 15, 2011

[3] Yufeng Guo, et al., International Journal of Electrical Power \& Energy Systems 129, 106804 (2021), https://doi.org/10.1016/j.ijepes.2021.106804.

[4] N. Hatziargyriou et al., IEEE Transactions on Power Systems 36(4), 3271 (2021), doi: 10.1109/TPWRS.2020.3041774

[5] D. Sanchez, J.L. Domínguez-García et al., Sustainablility (MDPI) 12(4), 1527 (2020)

[6] P. Stefanidou-Voziki, C. Corchero, J.L. Domínguez-García "A Practical Algorithm for Fault Classification in Distribution Grids" 2020 IEEE International Conference on Environment and Electrical Engineering and 2020 IEEE Industrial and Commercial Power Systems Europe (EEEIC/I\&CPS Europe)

[7] A. Ivanova, P. Paradell, J.L. Domínguez-García, A. Colet "Intentional Islanding of Electricity Grids using Binary Genetic Algorithm" $2^{\text {nd }}$ Global Power, energy and Communication Conference (GPECOM), 2020, pp. 297-301 


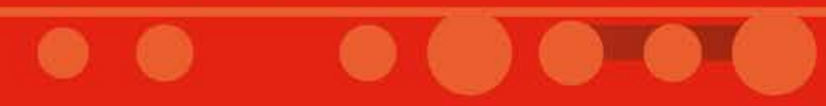

\section{PLAN to PARTICIPATE}

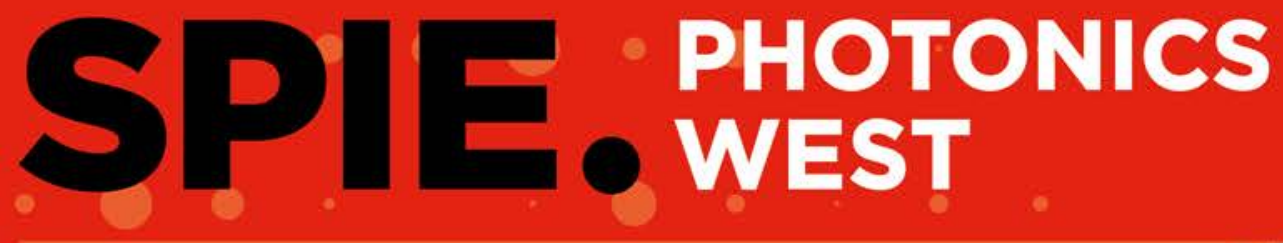

\section{PHOTONICS} WEST

THE WORLD'S PREMIER LASERS, BIOMEDICAL OPTICS, AND OPTOELECTRONICS EVENT

.00000000

- 1.0000

We look forward to safely gathering in San Francisco for SPIE Photonics West. Please consider attending and hear about the latest research in biomedical optics, biophotonics, industrial lasers, optoelectronics, microfabrication, MOEMS-MEMS, displays, and more. Attend and join us in San Francisco. Registration opens soon. 